\title{
Suscetibilidade de Rhipicephalus (Boophilus) microplus a carrapaticidas em Mato Grosso do Sul, Brasil
}

\author{
Susceptibility of Rhipicephalus (Boophilus) microplus to acaricides in Mato Grosso do Sul, Brazil
}

\author{
Alberto Gomes ${ }^{\mathrm{I}}$ Wilson Werner Koller ${ }^{\mathrm{II}}$ Antonio Thadeu Medeiros de Barros ${ }^{\mathrm{III}}$
}

\section{RESUMO}

\begin{abstract}
O carrapato bovino, Rhipicephalus (Boophilus) microplus, destaca-se dentre os ectoparasitas de importância econômica à pecuária nacional, tornando-se necessária a adoção de medidas de controle, particularmente em rebanhos Bos taurus e seus cruzamentos. O controle do carrapato tem sido cada vez mais difícil devido à constatação de populações resistentes aos diversos produtos em uso. Neste estudo, teve-se por objetivo conhecer a suscetibilidade desse carrapato a acaricidas em Mato Grosso do Sul. De outubro de 2003 a outubro de 2006, testes carrapaticidogramas foram realizados em onze das principais regiões pecuárias do estado. Nos testes de suscetibilidade, foi utilizada a técnica de imersão de adultos, com posterior avaliação de parâmetros biológicos. Foram testados doze acaricidas comerciais, abrangendo sete princípios ativos (isoladamente ou em associação), pertencentes a três grupos químicos: amidinas (amitraz), piretróides sintéticos (cipermetrina) e organofosforados (clorfenvinfós, clorpirifós, diazinon, diclorvós e etion). Baixa suscetibilidade foi detectada em todas as propriedades, evidenciando uma reduzida eficácia de todos os grupos químicos testados. Apesar da grande variação de suscetibilidade demonstrada pelas distintas populações a cada acaricida testado, foi possivel observar um gradiente de eficácia desses produtos. Independente da classe, a eficácia média dos produtos com um único princípio ativo (19,94\%-64,27\%) foi, de modo geral, menor que a das associações, tanto entre piretróide e organofosforados (46,38\%$82,68 \%)$, como exclusivamente entre organofosforados (85,28\%-97,68\%). A associação contendo piretróide, organofosforados, sinergista e repelente (cipermetrina + clorpirifós + butóxido de piperonila + citronelal) apresentou $100 \%$ de eficácia, embora testada em menor número de populações. Embora comparações com cepas suscetíveis não tenham sido efetuadas, a baixa suscetibilidade demonstrada
\end{abstract}

aos distintos produtos testados sugere que a resistência do carrapato a diferentes classes esteja amplamente disseminada no Estado, motivo pelo qual recomenda-se a realização rotineira de testes de suscetibilidade antes da seleção e aplicação de produtos acaricidas para controle do carrapato.

Palavras-chave: carrapato bovino, acaricidas, controle químico, resitência.

\section{ABSTRACT}

The cattle tick, Rhipicephalus (Boophilus) microplus, is one of the most important ectoparasites of bovines, requiring adoption of control measures mainly in Bos taurus herds and its crossbreeds. Its control has becoming increasingly difficult due to selection of resistant populations by commercial products. This study aimed to know the status of cattle tick resistance to acaricides in the state of Mato Grosso do Sul. From October 2003 to October 2006 acaricide bioassays were conducted on cattle ticks from eleven of the most important livestock regions of the state. Adult immersion tests using regular commercial products according to label recommendations were followed by the evaluation of biological parameters. Twelve acaricide products containing one or more of seven active ingredients, from three chemical classes: amidine (amitraz), synthetic pyrethroid (cypermethrin), and organophosphates (chlorfenvinphos, chlorpyriphos, diazinon, dichlorvos, and ethion) were tested. Low tick susceptibility was observed in all ranches, with several populations showing virtually no susceptibility to one or more products. Despite the great variation of susceptibility shown by the populations to each acaricide, a gradient of efficacy of these products was observed. Regardless of the acaricide class, the average efficacy of products containing a single active ingredient (19.94\%-64.27\%) was generally lower than that showed by the mixtures, pyrethroid-

IEmbrapa Gado de Corte, Campo Grande, MS, Brasil.

IISanidade Animal, Embrapa Gado de Corte, Rodov. BR 262, km 4, CP 154, 79002-970, Campo Grande, MS, Brasil.

E-mail: koller@cnpgc.embrapa.br. Autor para correspondência.

"I'Laboratório de Parasitologia, Embrapa Pantanal, Corumbá, MS, Brasil. 
organophosphate (46.38\%-82.68\%) and between organophosphates (85.28\%-97.68\%). The mixture containing pyrethroid $+\mathrm{OF}+$ synergist + repellent (cypermethrin + chlorpyrifos + citronellal + piperonyl butoxide) showed $100 \%$ efficacy, although it was tested in a smaller number of populations. Although comparisons with a susceptible strain have not been made, the low efficacy showed by the several different products tested, strongly suggests that tick resistance is widespread in the state. For this reason, it is recommended the routine peruse of susceptibility tests before selection and use of acaricide products for tick control.

Key words: cattle tick, acaricides, chemical control, resistance.

\section{INTRODUÇÃO}

O carrapato bovino, Rhipicephalus (Boophilus) microplus (Acari: Ixodidae), causa à pecuária nacional prejuízos superiores à US $\$ 2$ bilhões anuais (GRISI et al., 2002). A dificuldade de controle e os prejuízos decorrentes tendem a ser mais expressivos em rebanhos com predominância de raças taurinas, as quais são marcadamente mais sensíveis ao carrapato que as raças zebuínas (OLIVEIRA \& ALENCAR, 1990; VERÍSSIMO et al., 2002).

Independente da raça, as infestações por esse parasita são importantes não apenas devido à sua ação espoliativa ou tóxica, mas também pela transmissão dos agentes da "Tristeza Parasitária Bovina" (GOMES, 1998). Apesar de sua importância econômica e das consequências de seu controle químico inadequado, inexiste um programa oficial, de âmbito nacional, de controle ou manejo integrado do carrapato bovino.

Na prática, o uso incorreto e indiscriminado dos acaricidas pode acelerar o processo de seleção de resistência a diferentes bases químicas, possibilitando a ocorrência de resistência múltipla ou cruzada. No Brasil, a seleção de populações resistentes vem ocorrendo não apenas com relação ao carrapato (FREITAS et al., 2005; ROCHA et al., 2006; FARIAS et al., 2008) mas também à mosca-dos-chifres, Haematobia irritans (BARROS et al., 2007), já que, por inespecificidade da grande maioria dos produtos utilizados, o controle de uma espécie tende a afetar a suscetibilidade da outra.

A elevada frequência de tratamentos, associada ao uso inadequado dos produtos, tem selecionado populações de carrapatos resistentes aos poucos grupos acaricidas existentes no mercado nacional em todas as regiões do país onde estudos desta natureza têm sido realizados, incluindo o CentroOeste (SILVA et al., 2000; FERNANDES, 2001), Nordeste (OLIVEIRA \& AZEVEDO, 2002; CAMPOS JÚNIOR \& OLIVEIRA, 2005; SILVA et al., 2005), Sudeste (LEITE,
1988; SOARES et al., 2001; FURLONG et al., 2007; MENDES et al., 2007) e Sul (MARTINS, 1996; SOUZA et al., 2003; FARIAS et al., 2008; CAMILLO et al., 2009).

O presente estudo foi conduzido com o propósito de realizar um diagnóstico inicial da situação da suscetibilidade de populações do carrapato a acaricidas comerciais em Mato Grosso do Sul (MS), o que subsidiará a definição de orientações técnicas mais adequadas ao manejo desse parasita. Além disso, considerando-se a abrangência territorial implícita, este trabalho terá continuidade no monitoramento da resistência desse parasita com proposta de disponibilização futura das informações na forma de um mapa eletrônico na página da Embrapa Gado de Corte.

\section{MATERIAL E MÉTODOS}

As avaliações de suscetibilidade foram conduzidas durante três anos, de outubro de 2003 a outubro de 2006, em populações de carrapatos oriundas de propriedades de gado de corte e de leite, a partir de carrapatos coletados uma única vez em cada propriedade visitada.

Para a realização dos testes carrapaticidas, foram selecionadas propriedades em 39 municípios, contemplando todas as microrregiões, conforme detalhamento a seguir, observando-se entre parênteses o número de propriedades visitadas (= número de testes realizados) nos respectivos municípios: Alto Taquari [Bandeirantes (4), Camapuã (2), Rio Negro (2), Rio Verde (1), Rochedo (3) e São Gabriel(2)]; Aquidauana [Anastácio (1), Aquidauana (2) e Dois Irmãos (6)]; Baixo Pantanal [Porto Murtinho(1)]; Bodoquena [Bela Vista (1), Bonito (2) e Caracol(1)]; Campo Grande [Campo Grande (18), Jaraguari (1), Sidrolândia (1) e Terenos(1)]; Cassilândia [Chapadão do Sul (4) e Costa Rica(1)]; Dourados [Angélica (5), Dourados (3), Glória de Dourados (2), Maracaju (1), Nova Alvorada (1), Ponta Porã (4), Rio Brilhante (1) e Vicentina (1)]; Iguatemi [Amambai (1), Eldorado (4), Iguatemi (2), Naviraí (1) e Paranhos (1)]; Nova Andradina [Bataguassu (3) e Nova Andradina (1)]; Paranaíba [Aparecida do Taboado (1) e Paranaíba (1)] e Três Lagoas [Água Clara (6), Ribas do Rio Pardo (2) e Três Lagoas (3)].

A seleção das propriedades amostradas priorizou aquelas com histórico de problemas no controle químico do carrapato (ROULSTON et al., 1981). Entretanto, na ausência de infestações suficientes nestas propriedades para a realização dos testes, as amostragens foram realizadas conforme a disponibilidade de carrapatos em outras propriedades, tendo-se por norma utilizar apenas carrapatos obtidos 
de animais não submetidos a banhos carrapaticidas nos últimos 21 dias.

Para a avaliação in vitro da suscetibilidade, foi empregado o Teste de Imersão de Adultos (AIT) (DRUMMOND et al., 1973), também conhecido como "biocarrapaticidograma". Foram utilizados doze produtos acaricidas (formulação emulsionável) diluídos na concentração indicada pelo fabricante. Princípios ativos, respectivas concentrações e número de testes realizados foram: amitraz 12,5\% $(\mathrm{n}=104)$, diazinon $50 \%$ $(n=99)$, cipermetrina $15 \%(n=102)$, cipermetrina $2,5 \%+$ cimiazole $17,5 \%(n=93)$, cipermetrina $2,5 \%+$ clorfenvinfós $13,8 \%(n=14)$, cipermetrina $20 \%+$ clorpirifós $50 \%(\mathrm{n}=57)$, cipermetrina $4,5 \%$ + diclorvós (DDVP) $50 \%(\mathrm{n}=62)$, cipermetrina $8 \%$ + etion $60 \%$ ( $\mathrm{n}=66)$, DDVP 60\% + clorfenvinfós 20\% ( $\mathrm{n}=94)$, DDVP $60 \%+$ clorpirifós $20 \%(n=56)$, cipermetrina $15 \%+$ clorpirifós $25 \%$ + citronelal $1 \%(n=53)$ e cipermetrina $15 \%+$ clorpirifós $25 \%$ + butóxido de piperonila $15 \%+$ citronelal $1 \%(n=14)$. Os produtos comerciais testados foram selecionados em função de seus princípios ativos e grupos químicos e/ou devido a seu uso na região. Sua menção no presente estudo não constitui recomendação da Embrapa quanto a seu uso.

Em cada propriedade, foram coletadas, no mesmo dia, cerca de 150 teleóginas de vários animais do rebanho. Os carrapatos foram lavados em água corrente limpa, secos com papel absorvente e selecionados quanto ao seu vigor, motilidade e peso, antes de serem distribuídos em placas de Petri para formar grupos homogêneos com dez teleóginas. Os lotes de teleóginas foram imersos por cinco minutos (MENDES et al., 2000) tanto nas soluções de cada produto como no controle (imersão em água). Em seguida, as teleóginas foram secas sobre papel toalha e colocadas em placas de Petri mantidas em estufa tipo B.O.D. com temperatura de $\pm 27^{\circ} \mathrm{C}$ e UR $>80 \%$, por 16 dias. Ao final deste período, efetuou-se a avaliação das posturas.

Depois de pesadas, as posturas foram colocadas em tubos de tela galvanizada vedados com tampas de algodão, sendo, então, mantidos em posição vertical na estufa por 24 dias nas condições de temperatura e umidade mencionadas. Ao final desse período, as larvas eram imobilizadas em congelador e transferidas, juntamente com eventuais ovos inviáveis, para frascos com álcool $70^{\circ} \mathrm{GL}$. As leituras para a determinação dos percentuais de eclosão foram efetuadas com o auxílio de microscópio estereoscópico. A taxa de eclosão foi considerada como sendo a média dos percentuais de eclosão obtidos em três amostras com cerca de duzentos ovos e/ou larvas cada.

Para o cálculo da eficácia dos produtos testados (DRUMMOND et al., 1973; SONENSHINE, 1991), foram determinados os seguintes parâmetros biológicos: peso das teleóginas, peso da postura, taxa de eclosão e eficiência reprodutiva. Foram considerados eficazes os produtos que apresentaram controle igual ou superior a $95 \%$ nos testes, conforme norma vigente (BRASIL, 1997).

\section{RESULTADOS E DISCUSSÃO}

Dentre os doze produtos avaliados e utilizados em MS, apenas duas (16,67\%) associações apresentaram eficácia média nos testes in vitro superior a $95 \%$ (Tabela 1). O produto contendo DDVP $60 \%+$ clorfenvinfós $20 \%$ apresentou eficácia média de $97,68 \%$, entretanto, a amplitude da eficácia observada nos testes $(48,24 \%-100 \%)$ evidenciou que a suscetibilidade

Tabela 1 - Eficácia de produtos carrapaticidas em testes de imersão de teleóginas do carrapato bovino, Rhipicephalus (Boophilus) microplus, no período de outubro/2003 a outubro/2006, em Mato Grosso do Sul.

\begin{tabular}{lcc}
\hline Princípio ativo e concentração & Amplitude & Média \\
\hline 1. Amitraz 12,5\% & $0-100$ & 64,27 \\
2. Diazinon 50\% & $0,03-100$ & 56,65 \\
3. Cipermetrina 15\% & $0,03-96,15$ & 19,94 \\
4. Cipermetrina 2,5\% + cimiazole 17,5\% & $0-100$ & 68,69 \\
5. Cipermetrina 2,5\% + clorfenvinfós 13,8\% & $9,94-100$ & 57,74 \\
6. Cipermetrina 20\% + clorpirifós 50\% & $16,71-100$ & 82,68 \\
7. Cipermetrina 4,5\% + diclorvós (DDVP) 50\% & $0-100$ & 46,38 \\
8. Cipermetrina 8\% + etion 60\% & $0-100$ & 60,64 \\
9. DDVP 60\% + clorfenvinfós 20\% & $48,24-100$ & 97,68 \\
10. DDVP 60\% + clorpirifós 20\% & $25,01-100$ & 85,28 \\
11. Cipermetrina 15\% + clorpirifós 25\% + citronelal 1\% & $0-100$ & 74,53 \\
12. Cipermetrina 15\% + clorpirifós 25\% + butóxido de piperonila 15\% + citronelal 1\% & - & 100 \\
\hline
\end{tabular}

Ciência Rural, v.41, n.8, ago, 2011. 
a este produto encontrava-se comprometida em algumas propriedades. Por outro lado, o produto à base de cipermetrina $15 \%$ + clorpirifós $25 \%$ + butóxido de piperonila $15 \%$ + citronelal $1 \%$ apresentou o melhor desempenho dentre os produtos testados, atingindo 100\% de eficácia nos 14 testes realizados. Considerando o lançamento relativamente recente deste produto, seu uso criterioso torna-se estratégico e fundamental para retardar possível surgimento de resistência. Por ser um produto há pouco tempo disponível no comércio, um menor número de testes foi realizado com ele.

Independente do grupo químico (amidina, organofosforado ou piretróide), todos os produtos com um único princípio ativo apresentaram eficácia média inferior a $65 \%$. Mesmo considerando as associações entre princípios ativos, mais da metade $(58,3 \%)$ dos produtos testados não alcançou $70 \%$ de eficácia média, evidenciando a grave situação da resistência do carrapato bovino às principais bases carrapaticidas em uso no MS.

$\mathrm{O}$ produto exclusivamente à base de cipermetrina apresentou a menor eficácia média $(19,94 \%)$ dentre os produtos testados, apresentando nível de eficácia satisfatório em apenas uma propriedade. Contudo, este princípio ativo encontra-se presente na maioria $(77,8 \%)$ das associações testadas. Paralelamente, torna-se importante ressaltar a pressão de seleção exercida pelo uso de organofosforados, presentes em $88,9 \%$ das associações testadas, o que contribui para explicar a ampla resistência observada a princípios ativos desta classe.

Em todas as propriedades visitadas verificou-se resistência a pelo menos um dos produtos testados, constatando-se, em diversas propriedades, a ocorrência de níveis de resistência de até $100 \%$ a mais de um produto, por vezes envolvendo distintas classes. De modo geral, essa situação se repete nas distintas microrregiões que compõem o estado.

Situações semelhantes com respeito aos principais princípios ativos utilizados têm sido relatadas em outras localidades do país, conforme autores elencados no penúltimo parágrafo da introdução deste artigo, variando apenas o nível de resistência aos princípios ativos, o que resulta, em última análise, das práticas de manejo sanitário adotadas em cada propriedade. De modo geral, este estudo evidencia a ampla ocorrência de resistência múltipla à maioria das classes de carrapaticidas disponíveis no mercado nacional.

A partir de amostras de carrapatos coletadas em Minas Gerais e em estados vizinhos, FURLONG et al. (2007) constataram que apenas dois dentre os 24 produtos acaricidas avaliados apresentaram eficácia satisfatória, sendo o mais eficaz o que se destacou no presente trabalho, ou seja, a associação cipermetrina + clorpirifós + butóxido de piperonila + citronelal, com 99,8\% de eficácia, seguida da cipermetrina + clorpirifós $(98,9 \%)$. No presente estudo, este último produto apresentou eficácia entre $16,71 \%$ e $100 \%$ (média de $82,68 \%$ ), evidenciando a ocorrência de resistência não apenas ao piretróide mas também ao organofosforado em algumas propriedades amostradas no MS. MENDES et al. (2001), em levantamento realizado em diferentes regiões de São Paulo, observaram maior suscetibilidade do carrapato ao amitraz $(81,42-95,83 \%)$ e à associação cipermetrina + clorfenvinfós $(66,27 \%$ - 94,4\%), embora esses resultados denotem a ocorrência de resistência a ambos os produtos naquele estado.

Um agravante com relação à situação da resistência dos carrapatos é representado pela frequente constatação de falhas de manejo na maioria das propriedades, tais como: uso sistemático de um único produto ou classe acaricida, tratamento vinculado à ocorrência de formas adultas, número excessivo de aplicações anuais (MARTINS, 2004; FURLONG et al., 2007; FARIAS et al., 2008) e controle inadequado da mosca-dos-chifres (BARROS, 2005). De modo geral, constata-se uma elevada deficiência quanto ao acesso a informações técnicas que embasem o correto uso de produtos antiparasitários. Percebe-se, também, uma clara resistência ou negligência dos produtores quanto à adoção de recomendações técnicas já conhecidas como, por exemplo, o manejo estratégico proposto por FURLONG et al. (2003).

Embora o controle químico apresente limitações, formas alternativas de controle do carrapato, tais como a aplicação de imunoterápicos (vacinas) e o controle biológico, respectivamente, ainda não atendem o grau necessário de imunização ou não são viáveis para grandes rebanhos (FREITAS et al., 2005). Por sua vez, a utilização de inseticidas naturais ou fitoterápicos, de modo geral, tem gerado resultados contraditórios com relação ao controle do carrapato bovino, em especial quanto à validação no campo dos resultados observados em laboratório (MATIAS et al., 2003; CHAGAS, 2004).

Os resultados aqui apresentados constituem o primeiro diagnóstico sistematizado da situação da resistência do carrapato bovino aos carrapaticidas nas principais microrregiões pecuárias de MS. O problema da resistência no MS é evidente e similar a outras regiões do país e tende a agravar-se, tornando cada vez mais complexa a definição de recomendações técnicas que possam aliar medidas de controle parasitário ao manejo da resistência. 


\section{CONCLUSÃO}

A eficácia de produtos contendo associações foi, em geral, maior que a de produtos contendo um único princípio ativo, aumentando a probabilidade de um controle satisfatório do carrapato na maioria das propriedades.

Em todas as propriedades amostradas em Mato Grosso do Sul, foi observada baixa suscetibilidade de carrapaticidas comerciais, evidenciando uma reduzida eficácia de todos os grupos químicos testados. Esses resultados sugerem a ampla ocorrência de resistência do carrapato a todos os grupos químicos testados (amidinas, organofosforados e piretróides sintéticos).

\section{AGRADECIMENTOS}

Aos proprietários e funcionários das fazendas visitadas, pelo o apoio logístico. Aos extensionistas que agendaram e acompanharam as visitas e, em especial, ao técnico agrícola Ronaldo Luiz da Silva, que auxiliou na realização dos testes.

\section{REFERÊNCIAS}

BARROS, A.T.M. Aspectos do controle da mosca-doschifres e manejo de resistência. Corumbá: Embrpa Pantanal, 2005. 23p. (Embrapa Pantanal. Documentos, 77).

BARROS, A.T.M. et al. Inseticide susceptibility of horn flies, Haematobia irritans (Diptera: Muscidae), in the State of Mato Grosso do Sul, Brazil. Revista Brasileira de Parasitologia Veterinária, v.16, n.3, p.145-151, 2007. Disponível em: <http://www.cbpv.com.br/rbpv/documentos/1632007/ c163145_151.pdf>. Acesso em: 23 fev. 2011.

BRASIL. Ministério da Agricultura e do Abastecimento. Secretaria de Defesa Agropecuária. Portaria n. 48 de 12 de maio de 1997. Regulamento técnico para licenciamento e/ou renovação de licença de produtos antiparasitários de uso veterinário. Diário Oficial da União [da] República Federativa do Brasil, Brasília, DF, 16 maio 1997. Seção 1. p.10165. Disponível em: <http://extranet.agricultura.gov.br/ sislegis-consulta/servlet/ VisualizarAnexo?id=2118>. Online. Acesso em: 29 set. 2010.

CAMILLO, G. et al. Eficiência in vitro de acaricidas sobre carrapatos de bovinos no estado do Rio Grande do Sul, Brasil. Ciência Rural, v.39, n.2, p.490-495, 2009. Disponível em: <http://www.scielo.br/pdf/cr/v39n2/a82cr262.pdf>. Acesso em: 23 fev. 2011. doi: 10.1590/S0103-84782008005000082.

CAMPOS JÚNIOR, D.A.; OLIVEIRA, P.R. Avaliação in vitro da eficácia de acaricidas sobre Boophilus microplus (Canestrini, 1887) (Acari: Ixodidae) de bovinos no município de Ilhéus, Bahia, Brasil. Ciência Rural, v.35, n.6, p.1386-1392, 2005. Disponível em: $<$ http://www.scielo.br/scielo.php?script=sci_arttext\&pid=S010384782005000600025>. Acesso em: 24 fev. 2011. doi: 10.1590/ S0103-84782005000600025.

CHAGAS, A.C.S. Controle de parasitas utilizando extratos vegetais. Revista Brasileira de Parasitologia Veterinária, v.13, Supl.1, p.156-160, 2004. Disponível em: <http:// www. scielo.br/scieloOrg/php/reflinks.php?refpid=S0103$8478200800070004800016 \&$ pid=S 0103 $84782008000700048 \& \operatorname{lng}=e n>$. Acesso em: 24 fev. 2011.

DRUMMOND, R.O. et al. Boophilus annulatus and $\boldsymbol{B}$. microplus: laboratory tests of insecticides. Journal of Economic Entomology, v.66, n.1, p.130-133, 1973. Disponível em: <http://www.scielo.br/scieloOrg/php/ reflinks.php?refpid=S19842961201000010000900010\&pid=S1984$29612010000100009 \& \operatorname{lng}=\mathrm{en}>$. Acesso em: 24 fev. 2011.

FARIAS, N.A. et al. Análise da eficácia de acaricidas sobre o carrapato Boophilus microplus, durante a última década, na região sul do Rio Grande do Sul. Ciência Rural, v.38, n.6, p.1700-1704, 2008. Disponível em: <http://www.scielo.br/scielo.php?pid=S0103$84782008000600032 \&$ script $=$ sci_arttext $>$. Acesso em: 24 fev. 2011. doi: $10.1590 / \mathrm{S} 0103-84782008000600032$.

FERNANDES, F.F. Efeitos toxicológicos e resistência a piretróides em Boophilus microplus de Goiás. Arquivo Brasileiro de Medicina Veterinária e Zootecnia, v.53, n.5, p.538-543, 2001. Disponível em: <http://www.scielo.br/scielo.php?pid=S0102$09352001000500004 \&$ script $=$ sci_arttext $>$. Acesso em: 24 fev. 2011. doi: $10.1590 /$ S0102-09352001000500004.

FREITAS, D.R.J. et al. Caracterização da resistência para acaricidas no carrapato Boophilus microplus. Acta Scientiae Veterinaria, v.33, n.2, p.109-117, 2005. Disponível em: <http:/ /www.scielo.br/scieloOrg/php/reflinks.php?refpid=S0085$5626200900030002000016 \&$ p id = S 0085 56262009000300020\&lng=en>. Acesso em: 24 fev. 2011.

FURLONG, J. et al. Carrapato dos bovinos: controle estratégico nas diferentes regiões brasileiras. Juiz de Fora: Embrapa Gado de Leite, 2003. 5p. (Embrapa Gado de Leite. Comunicado Técnico, 36).

FURLONG, J. et al. O carrapato dos bovinos e a resistência: temos o que comemorar? A Hora Veterinária, v.27, n.159, p.26-32, 2007. Disponível em : <http://www.scielo.br/scieloOrg/ $\mathrm{ph} \mathrm{p} / \mathrm{r}$ e f $1 \mathrm{inks}$. ph p ? ref p i d = S 0103 8478200900020002700008 \& pid=S 0103 $84782009000200027 \& \operatorname{lng}=e n>$. Acesso em: 24 fev. 2011.

GOMES, A. O carrapato-do-boi Boophilus microplus: ciclo, biologia, epidemiologia, patogenia e controle. In: KESSLER, R.H.; SCHENK, M.A.M. (Eds). Carrapato, tristeza parasitária e tripanossomose dos bovinos. Campo Grande: Embrapa Gado de Corte, 1998. Cap.1, p.9-44.

GRISI, L. et al. Impacto econômico das principais ectoparasitoses em bovinos no Brasil. A Hora Veterinária, v.21, n.125, p.8-10, 2002. Disponível em: <http:// www.scielo.br/scieloOrg/php/reflinks.php? refpid=S0103$8478201000030001700009 \&$ pid=S 0103 84782010000300017\&lng=en>. Acesso em: 24 fev. 2011.

LEITE, R.C. Boophilus microplus (Canestrini, 1887) susceptibilidade, uso atual e retrospectivo de carrapaticidas em propriedades das regiões fisiográficas da Baixada do Grande Rio e Rio de Janeiro: uma abordagem epidemiológica. 1988. 151f. Tese (Doutorado) - Curso de Pós-graduação em Parasitologia, Universidade Federal Rural do Rio de Janeiro, RJ. 
MARTINS, J.R. Situação da resistência a carrapaticidas no Rio Grande do Sul: diagnóstico de situação. Veterinaria, v.32, n.132, p.12-14, 1996.

MARTINS, J.R. Manejo da resistência aos carrapaticidas. Revista Brasileira de Parasitologia Veterinária, v.13, Supl.1, p.114115, 2004. Disponível em: <http://www.cppsul.embrapa.br/ unidade/publicacoes:list/223>. Acesso em: 24 fev. 2011.

MATIAS, R. et al. Estudo químico-farmacológico de Melia azedarach (Meliaceae) sobre Boophilus microplus. Ensaios e Ciência, v.7, n.2, p.283-293, 2003. (Somente impresso).

MENDES, M.C. et al. Determination of minimal immersion times for use in in vitro resistence tests with Boophilus microplus (Canestrini, 1887) engorged females and pyrethroid acaricides. Revista Brasileira de Parasitologia Veterinária, v.9, n.1, p.33-39, 2000. Disponível em: <http://www.cbpv.com.br/rbpv/ documentos/912000/c9133_39.pdf〉. Acesso em 28 fev. 2011.

MENDES, M.C. et al. Bioassays for measuring the acaricides susceptibility of cattle tick Boophilus microplus (Canestrini, 1887) in São Paulo state, Brazil. Arquivos do Instituto Biológico, v.68, n.2, p.23-27, 2001. Disponível em: <http:// www.biologico.sp.gov.br/docs/arq/V68_2/mendes.pdf>. Acesso em: 28 fev. 2011.

MENDES, M.C. et al. Sensitivity of Boophilus microplus (Acari: Ixodidae) to pyrethroids and organophosphate in farms in the Vale do Paraíba region, São Paulo, Brazil. Arquivos do Instituto Biológico, v.74, n.2, p.81-85, 2007. Disponível em: <http:// www.biologico.sp.gov.br/docs/arq/v74_2/mendes1.pdf>. Acesso em: 28 fev. 2011.

OLIVEIRA, G.P.; ALENCAR, M.M. Resistência de bovinos de seis graus de sangue Holandês-Guzerá ao carrapato (Boophilus microplus) e ao berne (Dermatobia hominis). Arquivo Brasileiro de Medicina Veterinária e Zootecnia, v.42, n.2, p.127-135, 1990.

OLIVEIRA, A.A.; AZEVEDO, H.C. Resistência do carrapato Boophilus microplus a carrapaticidas em bovinos de leite na região dos tabuleiros costeiros de Sergipe. Revista Científica Rural, v.7, n.2, p.64-71, 2002.

ROCHA, C.M.B.M. et al. Percepção dos produtores de leite do município de Passos, MG, sobre o carrapato Boophilus microplus
(Acari: Ixodidae), 2001. Ciência Rural, v.36, n.4, p.12351242, 2006. Disponível em: <http://www.scielo.br/pdf/cr/ v36n4/a29v36n4.pdf>. Acesso em: 28 fev. 2011.

ROULSTON, W.J. et al. A survey for resistance in cattle ticks to acaricides. Australian Veterinary Journal, v.57, n.8, p.362371, 1981 . Disponível em: <http://onlinelibrary.wiley.com/doi/ 10.1111/j.1751-0813.1981.tb00524.x/abstract>. Acesso em: 28 fev. 2011.

SILVA, M.C.L. et al. Avaliação in vitro da eficácia do clorfenvinfós e da cialotrina sobre o Boophilus microplus, colhidos em bovinos da bacia leiteira da microrregião de Goiânia, Goiás. Ciência Animal Brasileira, v.1, n.2, p.143-148, 2000. Disponível em: <http://www.revistas.ufg.br/index.php/ vet/article/view/244/216>. Acesso em: 28 fev. 2011.

SILVA, W.W. et al. Resistência de fêmeas ingurgitadas de Boophilus microplus e Rhipicephalus sanguineus (Acari: Ixodidae) a carrapaticidas no semi-árido paraibano: efeito da cipermetrina e do amitraz. Agropecuária Científica no Semi-Árido, v.1, n.1, p.59-62, 2005. Disponível em: <http:/ /www.ufcg.edu.br/ edufcg/filestodownload/revistas/ acsa_vol_1_n_1.pdf>. Acesso em: 28 fev. 2011.

SOARES, V.E. et al. Análise in vitro da ação de carrapaticidas em cepas de Boophilus microplus (Canestrini, 1887) colhidas de bovinos leiteiros da região Nordeste do estado de São Paulo. Semina: Ciências Agrárias, v.22, n.1, p.85-90, 2001. Disponível em: <http://www.uel.br/revistas/uel/index.php/ semagrarias/article/view/1995/1740>. Acesso em: 28 fev. 2011.

SONENSHINE, D.E. Biology of ticks. Oxford: Oxford University, 1991. V.2. 464p.

SOUZA, A.P. et al. Eficácia de carrapaticidas em rebanhos de bovinos leiteiros de municípios da região Centro Sul do Paraná. Revista de Ciências Agroveterinárias, v.2, n.2, p.131-135, 2003. Disponível em: <http://www.scielo.br/pdf/pvb/v29n1/ a10v29n1.pdf>. Acesso em: 28 fev. 2011.

VERÍSSIMO, C.J. et al. Infestação por carrapatos Boophilus microplus (ACARI: IXODIDAE) em vacas Gir, Holandesa e mestiça sob pastejo. Arquivos do Instituto Biológico, v.69, Supl., p.87-89, 2002. 